\title{
KETERBUKAAN KOMUNIKASI DALAM KONSELING PROGRAM PIK-R CERIA SENTUL
}

\section{THE COMMUNICATION OPENNESS IN THE PIK-R CERIA SENTUL COUNSELING PROGRAM}

\author{
Nurul Azmi Widyasari ${ }^{1}$, Sukarelawati ${ }^{2 *}$, Maria Fitriah ${ }^{3}$. \\ ${ }^{123}$ Program Studi Sains Komunikasi, Fakultas Ilmu Sosial dan Ilmu Politik, Universitas Djuanda Bogor Jl. Tol Ciawi \\ No 1 Kotak Pos 35 Bogor 16720 \\ *Korespondensi: sukarelawati@unida.ac.id
}

(Diterima oleh Dewan Redaksi: 01-08-2019)

(Dipublikasikan oleh Dewan Redaksi: 01-10-2019)

\begin{abstract}
Openness is the willingness of people to disclose information about themselves that might normally be hidden, provided that there are only a few appropriate disclosures (Devito, 2007). Openness in communication plays an important role in the counseling process. According to Sri Hastuti and Winkel (2007), counseling is giving advice in an interaction by exchanging ideas. With the openness in the counseling process, the purpose of a counseling will be easily achieved. This study aims to analyze the communication openness in the Ceria Sentul $P I K-R$ counseling program. This study uses a descriptive type method with a quantitative approach carried out by survey using data collection techniques. Primary data consists of the results of observations and questionnaires, while secondary data in the form of results from library studies, documentation and interviews. The results of the study were processed using a single data tabulation. The study sample was determined by nonprobability sampling technique and the sample used was taken from the population of ideal adolescents aged 10-24 years who had joined the Ceria Sentul PIK-R counseling activity. Sampling was determined using accidental sampling technique with a total sample of 30 respondents scattered in the CIKI Sentul PIK-R counseling activity. The results showed that the openness of communication in Ceria Sentul PIK$R$ counseling program had a good category. This can be seen from the majority of respondents who agree that openness is in the counseling process. The conclusion of this study is that the client is ready to be open or ready to open himself to the counselor.
\end{abstract}

Keywords: Communication; Openness; Counseling 


\begin{abstract}
ABSTRAK
Keterbukaan adalah kemauan orang untuk mengungkapkan informasi tentang dirinya yang mungkin secara normal disembunyikan, asalkan saja beberapa pengungkapan tepat (Devito, 2007). Keterbukaan dalam komunikasi sangat berperan penting dalam proses konseling. Menurut Sri Hastuti dan Winkel (2007), konseling merupakan pemberian nasehat dalam suatu interaksi dengan cara bertukar pikiran. Dengan adanya keterbukaan dalam proses konseling, maka tujuan suatu konseling akan mudah dicapai. Penelitian ini bertujuan untuk menganalisis keterbukaan komunikasi dalam konseling program PIK-R Ceria Sentul. Penelitian ini menggunakan metode jenis deskriptif dengan pendekatan kuantitatif yang dilakukan dengan survey menggunakan teknik pengumpulan data. Data primer terdiri dari hasil observasi dan kuesioner, sedangkan data sekunder berupa hasil dari studi kepustakaan, dokumentasi dan wawancara. Hasil penelitian diolah dengan menggunakan tabulasi data tunggal. Sampel penelitian ditentukan dengan teknik nonprobability sampling dan sampel yang digunakan diambil dari populasi remaja ideal usia 10 sampai 24 tahun yang belum menikah yang mengikuti kegiatan konseling PIK-R Ceria Sentul. Pengambilan sampel ditentukan menggunakan teknik accidental sampling dengan jumlah pengambilan sampel sebanyak 30 responden yang tersebar dalam kegiatan konseling PIK-R Ceria Sentul. Hasil penelitian menunjukkan bahwa keterbukaan komunikasi dalam konseling program PIK-R Ceria Sentul memiliki kategori baik. Hal tersebut dilihat dari mayoritas jawaban responden yang setuju bahwa keterbukaan (Openness) ada pada proses konseling. Kesimpulan dari penelitian ini klien siap terbuka atau siap membuka diri kepada konselor.
\end{abstract}

Kata Kunci: Komunikasi; Keterbukaan; Konseling

Nurul Azmi Widyasari, 2019. Keterbukaan Komunikasi dalam Konseling Program PIK-R Ceria Sentul. 


\section{PENDAHULUAN}

Menurut Miftah Thoha (dalam Pratama, dkk, 2015), keterbukaan merupakan aspek keinginan agar dapat terbuka dengan orang lain dan dapat menanggapi secara jujur informasi yang datang.

Keterbukaan dalam komunikasi sangat berperan penting dalam proses konseling. Menurut Sulistyawati (2011), konseling merupakan proses komunikasi yang berlangsung dan menyatu dengan semua aspek pelayanan Keluarga Berencana, bukan hanya informasi yang diberikan dan dibicarakan pada suatu kesempatan tetapi apa yang diharapkan mampu mengubah sikap seorang remaja. Dengan adanya keterbukaan dalam proses konseling, maka tujuan suatu konseling akan mudah dicapai.

Pola pergaulan bebas karena pengaruh era globalisasi ditambah dengan kondisi yang sangat mudah terpengaruh yang dapat membawa remaja Indonesia ke dalam tiga masalah besar, yaitu: pernikahan dini, seks pranikah serta NAPZA yang dikenal Triad KRR. Hal tersebut dapat menjadi permasalahan yang sangat besar karena menyangkut kesinambungan generasi manusia berkualitas. Apabila tidak dapat menyikapi dengan baik ketiga masalah ini, maka generasi muda akan rusak. Untuk dapat mempersiapkan generasi berikutnya yang lebih berkualitas, maka tiga masalah tersebut harus menjadi tanggung jawab bersama antara keluarga, lingkungan masyarakat dan negara. Oleh karena itu, remaja membutuhkan fasilitas untuk mendapatkan informasi berkaitan dengan dunia mereka. Salah satu wadah yang dapat memberikan informasi-informasi tersebut adalah PIK-R atau Pusat Informasi Konseling Remaja (www.bkkbn.go.id).

Berdasarkan hasil wawancara pada tanggal 20 maret 2019 dengan salah satu ketua PIK-R Ceria Sentul yaitu Tiara yang mengungkapkan bahwa PIK-R Ceria Sentul merupakan salah satu PIK remaja yang berada di Kabupaten Bogor dan dibentuk untuk menjadi jembatan remaja menuju manusia yang diidamkan oleh masyarakat dan sekaligus dikembangkan menjadi sahabat remaja khususnya di wilayah Kecamatan Babakan Madang dan di Kabupaten Bogor pada umumnya.

Berdasarkan uraian di atas, maka dapat diambil rumusan masalah yaitu bagaimana keterbukaan komunikasi dalam proses konseling PIK-R Ceria Sentul. Maka tujuan penelitian ini adalah untuk menganalisis mengenai keterbukaan komunikasi dalam proses konseling PIK-R Ceria Sentul.

\section{MATERI DAN METODE}

Penelitian ini menggunakan pendekatan kuantitatif. Pendekatan kuantitatif, menurut Tehubijuluw dan Sugiarto (2014) dilakukan dengan melihat alam semesta ini secara obyektif dan kemudian mencari keterkaitan hubungan yang dapat diukur melalui penetapan variabel dan verifikasi hipotesis, guna mengetahui dan memahami indikator keterbukaan dalam karakteristik komunikasi interpersonal. Adapun metode yang digunakan dalam penelitian ini adalah metode deskriptif analisis melalui teknik survey yang mengambil sampel dari suatu populasi dengan menggunakan kuesioner sebagai alat pengumpulan data dari responden, hasilnya disusun dan dipaparkan secara deskriptif dan dianalisis serta diinterpretasikan untuk melihat indikator keterbukaan dalam karakteristik komunikasi interpersonal.

Populasi pada penelitian ini adalah seluruh remaja ideal 10-24 tahun dengan status belum menikah yang mengikuti kegiatan program PIK-Remaja Ceria Sentul Kabupaten Bogor. Teknik pengambilan sampel dalam penelitian ini dipilih dengan menggunakan teknik sampling jenis nonprobability sampling, menurut Sugiyono (2014) adalah sampel yang tidak memberikan peluang atau kesempatan sama bagi setiap unsur atau anggota populasi untuk dipilih menjadi sampel. 
Teknik nonprobability sampling penelitian menggunakan teknik accidental sampling. Menurut Sugiyono (2007), definisi accidental sampling adalah teknik penentuan sampel berdasarkan kebetulan, yaitu siapa saja yang secara kebetulan bertemu dengan peneliti dapat digunakan sebagai sampel.

Menurut Gay (dalam Pratama, dkk, 2015) penentuan jumlah responden dilakukan dengan pertimbangan representasi dan keadaan khalayak pada umumnya dan merupakan ukuran yang dapat diterima dan memenuhi syarat suatu metode penelitian (minimal 30 orang) untuk jenis korelasional.

Sampel dalam penelitian ini adalah 30 responden dari remaja ideal 10 sampai 24 tahun dengan status belum menikah yang mengikuti kegiatan program PIKRemaja Ceria Sentul Kabupaten Bogor.
Teknik pengumpulan data dalam penelitian ini adalah data primer yang diperoleh dari hasil observasi dan angket/kuesioner. Sedangkan data sekunder diperoleh dari studi literatur/studi kepustakaan, dokumentasi dan wawancara.

Teknik analisis deskriptif menggunakan rumus Weight Mean Score (WMS) dihitung berdasarkan kecenderungan jawaban responden dengan ditentukan oleh kriteria penilaian berdasarkan skor variasi jawaban yang bergerak dari 1-5, dengan interval antara satu kriteria dengan yang lainnya diperoleh angka sebesar 0.8. Angka tersebut diperoleh setelah adanya nilai tertinggi yang dikurangi nilai terendah dibagi banyaknya alternatif jawaban.

HASIL DAN PEMBAHASAN

Tabel 1 Keterbukaan Komunikasi pada Proses Konseling PIK-R Ceria Sentul

\begin{tabular}{|c|c|c|c|c|c|c|c|c|}
\hline $\begin{array}{l}\mathrm{N} \\
\mathrm{O}\end{array}$ & PERNYATAAN & SS & $S$ & KS & TS & STS & M & Ket \\
\hline 1. & Siap berinteraksi dan membuka diri. & $\begin{array}{c}12 \\
(40 \%)\end{array}$ & $\begin{array}{c}18 \\
(60 \%) \\
\end{array}$ & 0 & 0 & 0 & 4,40 & $\begin{array}{c}\text { Sangat } \\
\text { Baik }\end{array}$ \\
\hline 2. & $\begin{array}{l}\text { Mengajukan pertanyaan tentang } \\
\text { kesehatan reproduksi. }\end{array}$ & $\begin{array}{c}12 \\
(40 \%)\end{array}$ & $\begin{array}{c}16 \\
(53 \%)\end{array}$ & $2(7 \%)$ & 0 & 0 & 4,33 & $\begin{array}{c}\text { Sangat } \\
\text { Baik }\end{array}$ \\
\hline 3. & $\begin{array}{l}\text { Mengajukan pertanyaan tentang } \\
\text { terhindar dari resiko seks bebas. }\end{array}$ & $\begin{array}{c}18 \\
(60 \%)\end{array}$ & $\begin{array}{c}12 \\
(40 \%) \\
\end{array}$ & 0 & 0 & 0 & 4,60 & $\begin{array}{c}\text { Sangat } \\
\text { Baik }\end{array}$ \\
\hline 4. & $\begin{array}{l}\text { Mengajukan pertanyaan tentang } \\
\text { resiko HIV/AIDS. }\end{array}$ & $\begin{array}{c}14 \\
(47 \%) \\
\end{array}$ & $\begin{array}{c}15 \\
(50 \%) \\
\end{array}$ & $1(3 \%)$ & 0 & 0 & 4,43 & $\begin{array}{c}\text { Sangat } \\
\text { Baik }\end{array}$ \\
\hline 5. & $\begin{array}{l}\text { Mengajukan pertanyaan tentang } \\
\text { resiko NAPZA (obat-obatan } \\
\text { terlarang). }\end{array}$ & $\begin{array}{c}14 \\
(47 \%)\end{array}$ & $\begin{array}{c}15 \\
(50 \%)\end{array}$ & $1(3 \%)$ & 0 & 0 & 4,43 & $\begin{array}{c}\text { Sangat } \\
\text { Baik }\end{array}$ \\
\hline 6. & $\begin{array}{l}\text { Menceritakan pengalaman temannya } \\
\text { seputar seks bebas, HIV/AIDS dan } \\
\text { NAPZA. }\end{array}$ & $\begin{array}{c}2 \\
(7 \%)\end{array}$ & $\begin{array}{c}20 \\
(67 \%)\end{array}$ & $\begin{array}{c}6 \\
(20 \%)\end{array}$ & $\begin{array}{c}1 \\
(3 \%)\end{array}$ & $\begin{array}{c}1 \\
(3 \%)\end{array}$ & 3,70 & Baik \\
\hline 7. & $\begin{array}{l}\text { Klien mengakui ketidaktahuannya } \\
\text { tentang kesehatan reproduksi. }\end{array}$ & $\begin{array}{c}3 \\
(10 \%)\end{array}$ & $\begin{array}{c}19 \\
(64 \%)\end{array}$ & $\begin{array}{c}7 \\
(23 \%)\end{array}$ & $1(3 \%)$ & 0 & 3,80 & Baik \\
\hline 8. & $\begin{array}{l}\text { Klien mengakui ketidaktahuannya } \\
\text { tentang resiko seks bebas. }\end{array}$ & $\begin{array}{c}5 \\
(17 \%)\end{array}$ & $\begin{array}{c}16 \\
(54 \%)\end{array}$ & $\begin{array}{c}7 \\
(23 \%)\end{array}$ & $1(3 \%)$ & $\begin{array}{c}1 \\
(3 \%)\end{array}$ & 3,73 & Baik \\
\hline 9. & $\begin{array}{l}\text { Klien mengakui ketidaktahuannya } \\
\text { tentang HIV/AIDS. }\end{array}$ & $\begin{array}{c}6 \\
(20 \%)\end{array}$ & $\begin{array}{c}13 \\
(43 \%)\end{array}$ & $\begin{array}{c}8 \\
(27 \%)\end{array}$ & $2(7 \%)$ & $\begin{array}{c}1 \\
(3 \%)\end{array}$ & 3,70 & Baik \\
\hline $\begin{array}{l}1 \\
0 .\end{array}$ & $\begin{array}{l}\text { Klien mengakui ketidaktahuannya } \\
\text { tentang NAPZA. }\end{array}$ & $\begin{array}{c}6 \\
(20 \%)\end{array}$ & $\begin{array}{c}15 \\
(50 \%)\end{array}$ & $\begin{array}{c}5 \\
(17 \%)\end{array}$ & $\begin{array}{c}4 \\
(13 \%)\end{array}$ & 0 & 3,76 & Baik \\
\hline $\begin{array}{l}1 \\
1 .\end{array}$ & $\begin{array}{l}\text { Mengakui atas pengalaman } \\
\text { temannya seputar seks bebas, } \\
\text { HIV/AIDS dan NAPZA. }\end{array}$ & $\begin{array}{c}4 \\
(13 \%)\end{array}$ & $\begin{array}{c}18 \\
(60 \%)\end{array}$ & $\begin{array}{c}5 \\
(17 \%)\end{array}$ & $2(7 \%)$ & $\begin{array}{c}1 \\
(3 \%)\end{array}$ & 3,73 & Baik \\
\hline
\end{tabular}

Sumber: Hasil penelitian 2019 
Berdasarkan hasil penelitian, keterbukaan komunikasi dalam proses konseling PIK-R Ceria Sentul memperoleh nilai akhir sebesar 4,05 pada kategori baik. Sebanyak 18 klien (60 persen) menyatakan sangat setuju dalam mengajukan pertanyaan yang tidak mereka ketahui tentang berperilaku sehat agar terhindar dari resiko seks bebas kepada konselor, dengan nilai tertinggi dari seluruh item yaitu 4,60 pada kategori sangat baik. Artinya klien aktif dalam menanyakan hal seputar resiko seks bebas kepada konselor karena seks bebas merupakan salah satu permasalahan terkompleks yang dialami oleh para remaja. Sedangkan penelitian yang dilakukan Pratama, dkk (2015) menyatakan pengaruh sosial media komunikasi interpersonal ibu dan anak yang meliputi keterbukaan komunikasi dalam membangun motivasi belajar memiliki hubungan yang rendah atau negatif.

Berdasarkan hasil wawancara pada tanggal 20 maret 2019 dengan salah satu responden sekaligus klien pada kegiatan konseling PIK-R Ceria Sentul yaitu Dedeh yang mengungkapkan bahwa di zaman milenial seperti ini informasi mengenai seks bebas sangat penting untuk diketahui khususnya oleh para remaja, karena dengan berkembangnya teknologi di zaman sekarang ini telah banyak memberi dampak negatif bagi para remaja sehingga menyebabkan terjadinya kenakalan remaja seperti seks bebas.

Menurut Desmita (2005), seks bebas adalah cara mengekspresikan dan melepaskan dorongan seksual yang berasal dari kematangan organ reproduksi, seperti berkencan intim dan bercumbu sampai melakukan kontak seksual. Perilaku tersebut tidak sesuai dengan norma karena remaja belum saatnya melakukan hal tentang seksual.

Menurut Dwi (2013), masa remaja merupakan suatu masa yang dimana siklus kehidupan sudah mencapai masa puncaknya. Pada masa ini, para remaja memiliki kesempatan yang besar untuk mengalami hal-hal yang baru serta menemukan sumber-sumber baru.

Rekapitulasi nilai akhir yang didapat dalam karakteristik keterbukaan berada pada kategori baik. Berdasarkan hasil wawancara pada tanggal 20 maret 2019 dengan salah satu konselor, yaitu Tiara, mengatakan bahwa dalam proses konseling ini diharapkan klien mampu untuk membuka dirinya kepada konselor karena pada tahap ini permasalahan akan terungkap.

\section{KESIMPULAN DAN IMPLIKASI}

\section{Kesimpulan}

Keterbukaan komunikasi dalam proses konseling PIK-R Ceria Sentul menunjukan nilai akhir sebesar 4,05 pada kategori baik. Klien aktif dalam menanyakan hal seputar resiko seks bebas kepada konselor karena seks bebas merupakan salah satu permasalahan terkompleks yang dialami oleh para remaja.

\section{Implikasi Teoritis}

Hasil penelitian ini dapat menambah pengetahuan tentang keterbukaan dalam berkomunikasi. Teori self disclosure menurut Johnson (dalam Supratiknya, 1995) adalah pengungkapan reaksi terhadap situasi yang sedang dihadapi oleh seseorang dengan memberikan informasi tentang masa lalunya yang relevan.

\section{Implikasi Praktis}

Hasil penelitian ini dapat membentuk klien lebih terampil melakukan komunikasi langsung secara interpersonal dan siap terbuka dalam berkomunikasi khususnya dalam kegiatan konseling. 


\section{DAFTAR PUSTAKA}

\section{Sumber Buku:}

A. Supratiknya. 1995. Tinjauan Psikologi Komunikasi Antar Pribadi. Yogyakarta: Kanisius (Anggota IKAPI).

Desmita. 2005. Psikologi Perkembangan. Bandung : Remaja Rosda Karya

DeVito, Joseph A. 2007. Buku Komunikasi Interpersonal, edisi ke-11. Boston: Pearson Education, Inc.

Hastuti, Sri dan Winkel. 2007. Bimbingan dan Konseling di Institusi Pendidikan. Yogyakarta : Media Abadi

Sugiyono. 2007. Metode Penelitian Bisnis, Bandung : Penerbit Alfabeta.

Sugiyono. 2014. Metode Penelitian Kuantitatif Kualitatif dan $R \& D$. Bandung : Alfabeta.

Sulistyawati, Ari. 2011. Pelayanan KB. Jakarta: Salemba Medika

Tehubijuluw, FK dan Sugiarto. 2014. METODOLOGI PENELITIAN Cara Mudah Membuat Makalah, Skripsi, Tesis, dan Disertasi. Tangerang : PT. Matana Bina Utama

\section{Sumber Skripsi:}

Pratama, DR, dkk. 2015. Pengaruh Sosial Media Komunikasi Interpersonal Ibu dan Anak dalam membangun Motivasi Belajar. Universitas Djuanda Bogor

Pristiwanti, Dwi Okta. 2013. Pergaulan Bebas Pada Remaja di Era Globalisasi. Universitas Negeri Semarang

Sumber Internet:

https://www.bkkbn.go.id/ (diakses pada tanggal 21 maret 2019, pukul 16:10) 